IJHER International Journal of Humanities and Educational Research ISSN: 2757-5403

Volume 4, Issue 1, February 2022

\title{
EXPLOITATION OF CHILDREN OVER THE INTERNET
}

\author{
Faiza DJADI 1 \\ Dr, Alger 1 University, Algeria \\ Latifa BOUSHABA 2 \\ Dr, Tiaret University, Algeria
}

\begin{abstract}
The development in the field of information and communication technologies, in particular the Internet, has had a great impact on the increase in the dangers that threaten children and the development of its methods. Despite the advantages given by this method, it had another aspect related to selfishness and an illegal attack on the child's life and privacy, which is known today as the Internet child. This method has inevitably entered the lives of children due to the spread of the Covid epidemic, and schools today are using it as a contemporary educational curriculum that helps develop the child's mental skills, creativity and innovation.

However, this use has become without guidance or supervision and the Internet spaces are open to all without restriction
\end{abstract}

Key words: Children, Exploit, A threat, Internet.

http://dx.doi.org/10.47832/2757-5403.12.8

f.djadi@univ-alger.dz, https://orcid.org/0000-0003-3470-5343

2 (D) latifa.boushaba@univ-tiaret.dz, https://orcid.org/0000-0002-7891-959X 


\title{
استغلال الأطفال عبر الأنترنت
}

\author{
جادي فايزة \\ د ، كلبة الحقوق بن يوسف بن خدة، الجز ائر \\ بوسحابة لطيفة

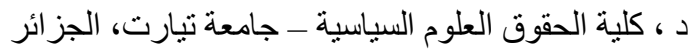

الملخص

لقد كان للتطور الحاصل في مجال تكنولوجيات الإعلام والاتصال وبصفة خاصة الانترنت الأثر البالغ في زيادة الأخطار

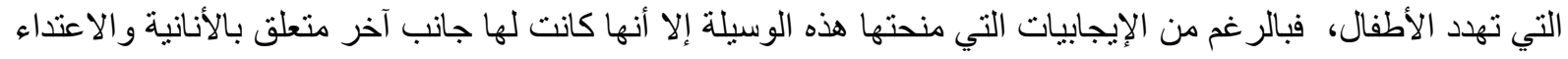

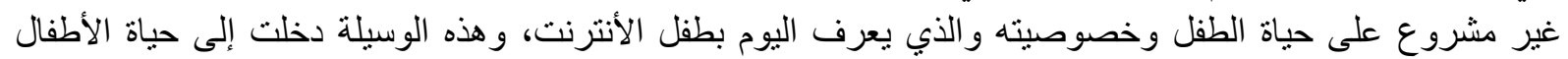

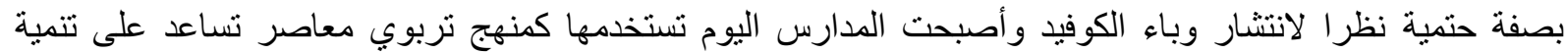
مهار ات الطفل العقلية والإبداع و الابتكار.

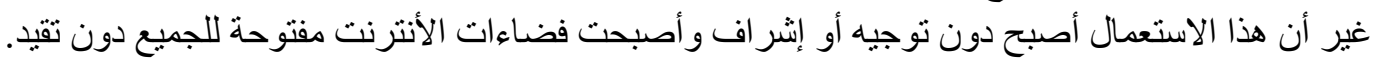
الكلمات المفتاحية: تحليل جغر افي، القوى العاملة التعليمية، التعليم الابتدائي.

مقدمة :

لقد عرف العالم الأنترنت على يد وزارة الدفاع الأمريكية،وأخذت الثبكة في التطور حتى أصبحت سهلة الاستخدام

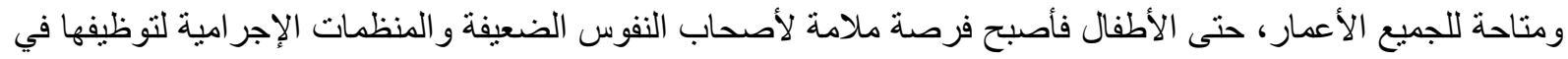

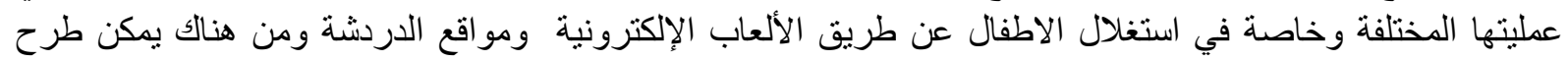
الإشكالية التالية: هل وفر المشرع الحماية الكافية للاستغلال الأطفال عبر الأنترنت؟ الإن

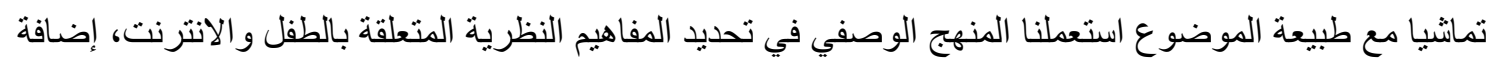

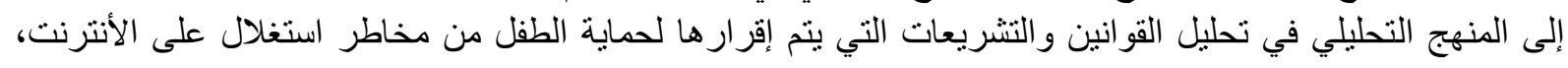

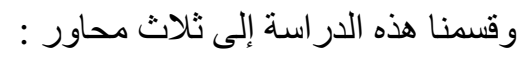

المحور الأول: الإطار الدفاهيمي للطفل و العوامل المؤدية بالطفل إلى الأنترنت

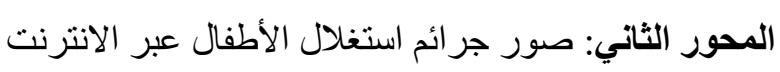
المحور الثالث: الحماية القانونية للمشر ع الجزائري من مخاطر الأنترنت على الاطفال . 


\section{أولا- المحور الأول: الإطار المفاهيمي للطقل والعوامل المؤدية بالطقل إلى الأنترنت}

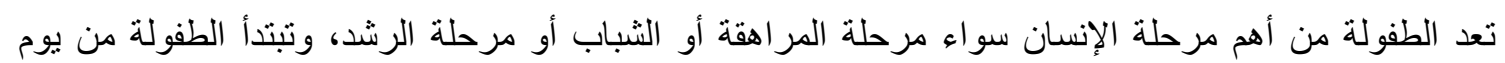

الو لادة وتتنهي عند سن البلوغ.

1

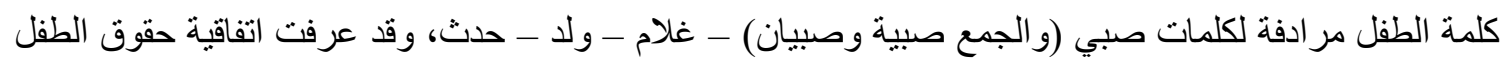

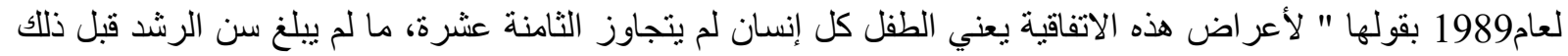

بموجب القانون المنطبق عليه"

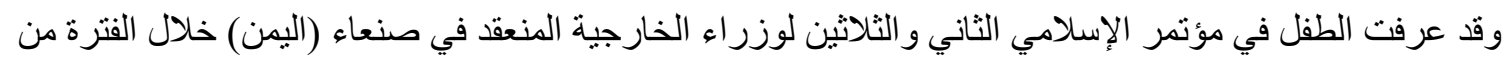

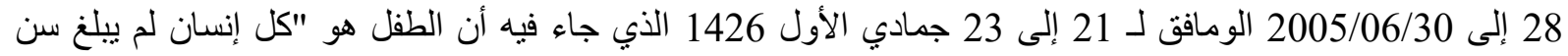

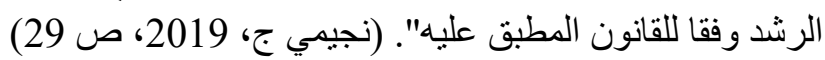

2-العوامل المؤدية بالطقل إلى الانترنت :

قبل التطرق إلى العو امل المؤدية بالطفل إلى الانترنت لابد من تعريف الانترنت.

ـ تعريف الانترنت:

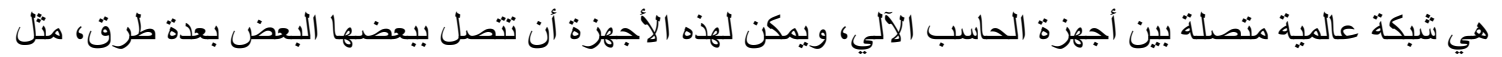

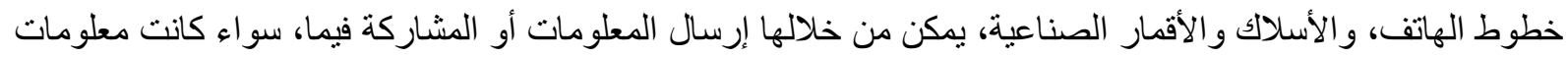

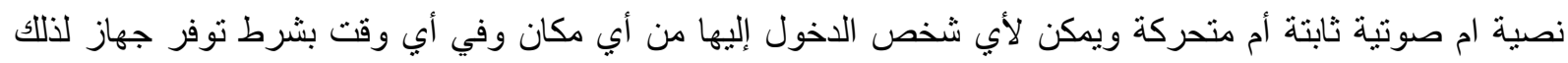
كهاتف أو حاسب آلي.

ومن اهم الجو انب الإيجابية للأنترنت في عصرنا هذا تتمثل في قضاء وقت ممتع في التسلية و الترفيه وذللك من

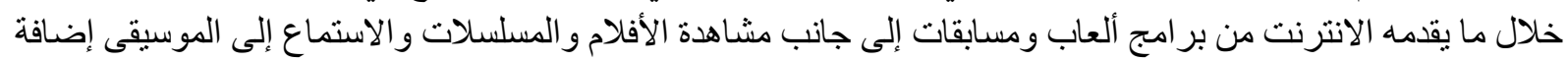

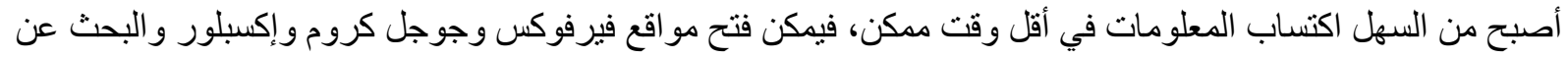

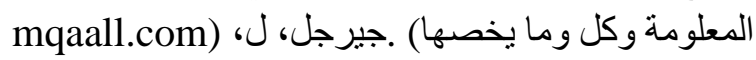

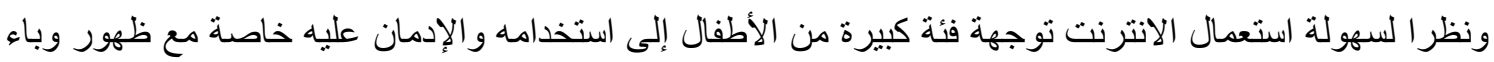
الكوفيد وغلق المدارس و المؤسسات الترفيهية الأخرى كالمكتبات، قاعات الرياضة، حدائق التسلية... غير أن هذا الاتجاه السلبي للانترنت لله عدة عو امل كالعامل الأسري و العامل العامل النفسي.

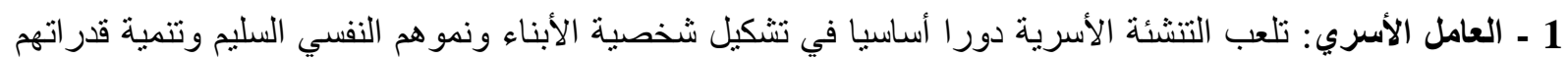

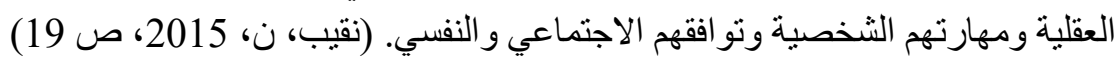
إلا أنه يزداد حدوث سوء معاملة الاطفال و إهمالهم في بعض الأسر نتيجة ظروفه الزهم الحياتية المتمنلة في البطالة، الخلافات الزوجية، الضغوط المالية والعزلة الاجتماعية، والعنف المنزلي مما أدى للأطفال إلى الإدمان في استخدام

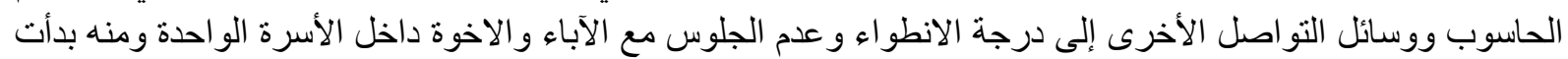

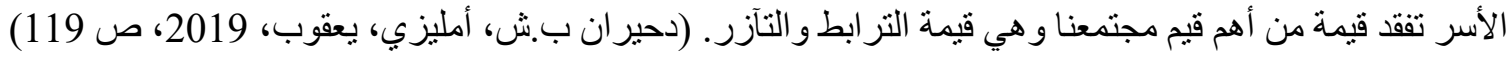
ويتيح الاستخدام الفردي لصفحات الانترنت و الغوص فيما تجاوز الكثير من الطابو هات والممنوعات التي حرم منها

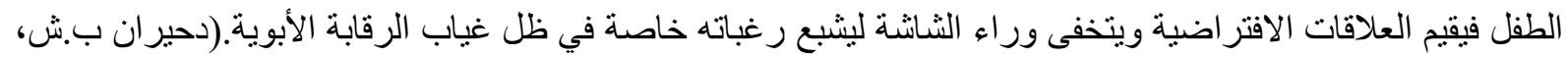

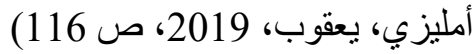
2 ـالعامل النفسي: تعد الإساءة النفسية هي كضربة قاضية على البنية والقيمة الذاتية للطفل و المتمثلة في تشويه النية السمعة و التحقير وتؤدي هذه الإساءة إلى بعض التصرفات التهات التي يقابلها الطفل من مواقف كالتهديد والخوف والألفاظ غير اللائقة

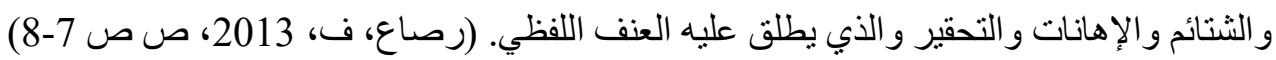

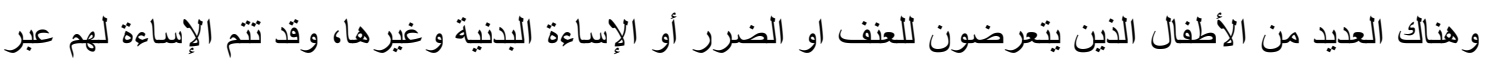

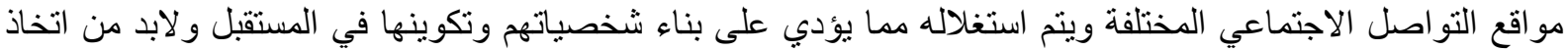

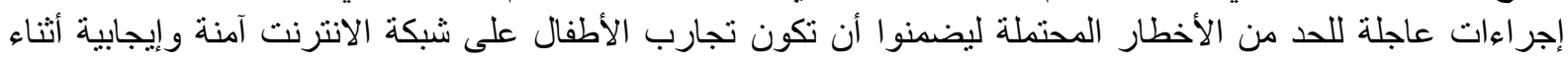
جائحة كوفيد 19) (UNICEF. Org/ar). 
ومن أمثلة عن بعض صور الجرائم استغلال الأطفال عبر الانترنت نتمثل في :

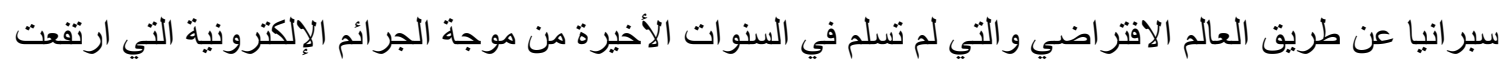

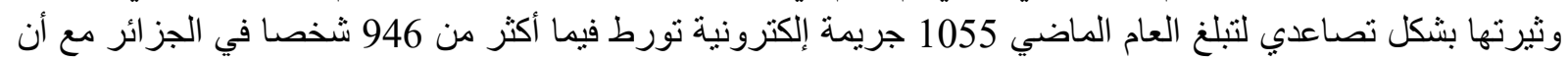

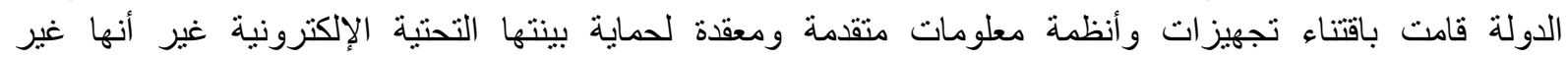

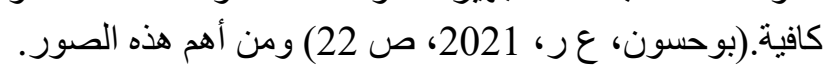
1-التحريض على العنف والتطرف عبر الانترنت :

و هذا من خلال بث الأفكار المنطرفة سواء كانت سياسية أو عنصرية او دينية، للسيطرة على وجدان الطفل

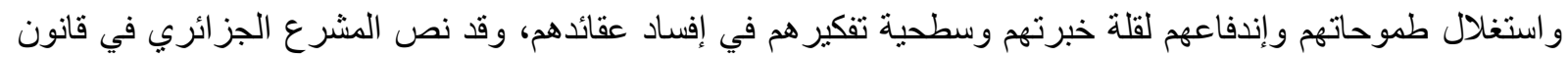

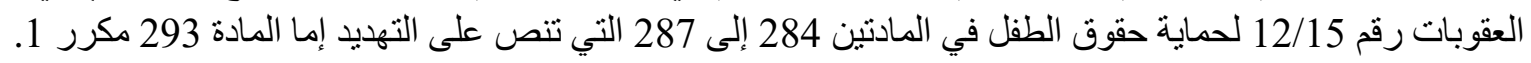

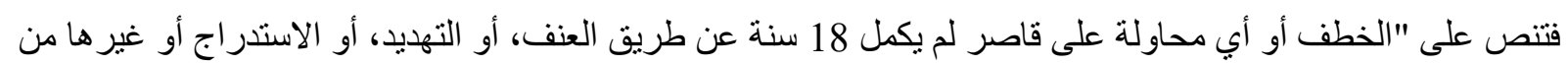

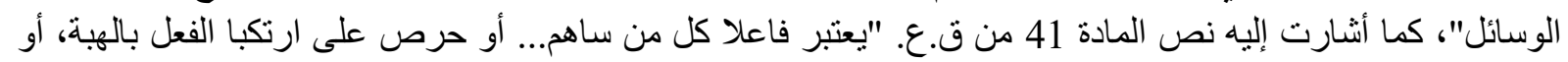

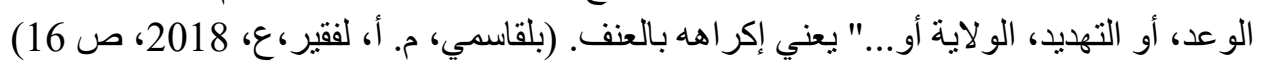
2- 2 جريمة التشهير عبر الأنترنت : التهدئ

يعد التشهير من الجر ائم الخطيرة تعني نشر و إذاعة معلومات شخصية للطفل الضحية، من أجل استغلالهاله، والإساءة

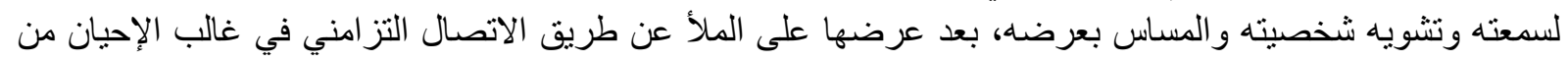

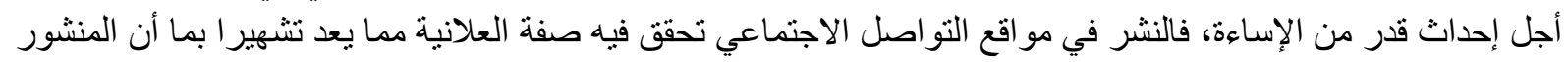

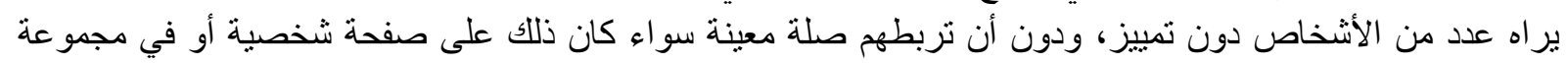
عامة أو مغلقة .

و الحصول على المعلومات السرية الثخصية للطفل يكون عن طريق الاختراق و السرقة أو بالثقة في الغير ونشر ها

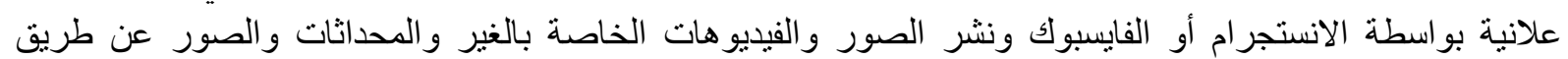

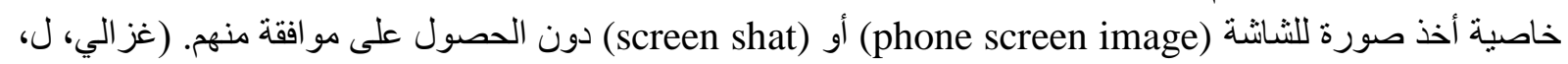

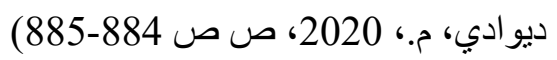

\section{3- جريمة الاستغلال الجنسي للأطفال عبر الانترنت:}

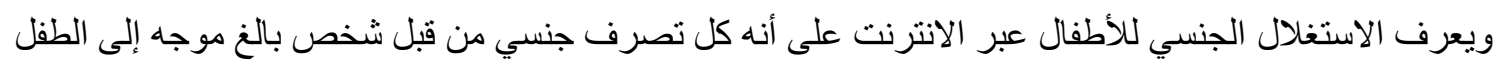

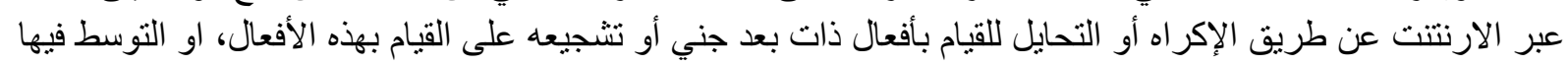

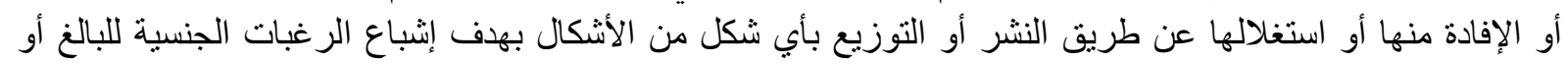

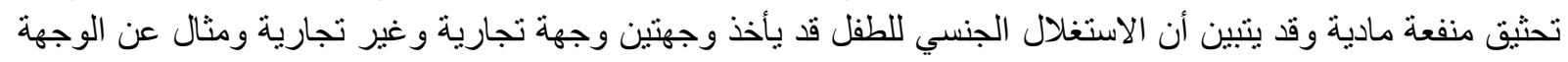

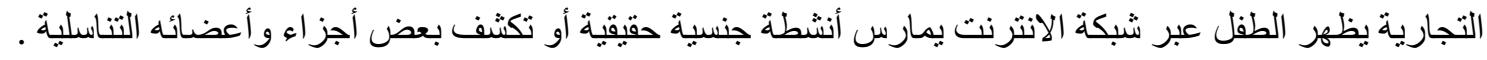

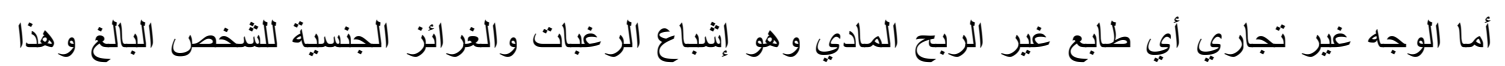

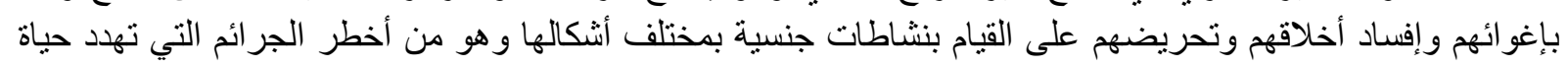

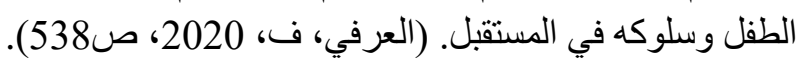




\section{المحور الثالث: الحماية القانونية للمشرع الجزائري من مخاطر الانترنت على الأطفال}

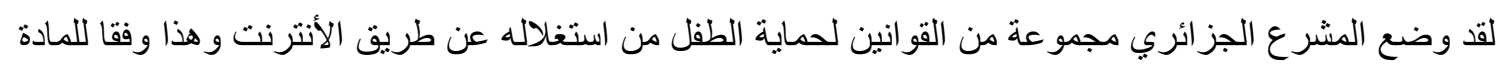

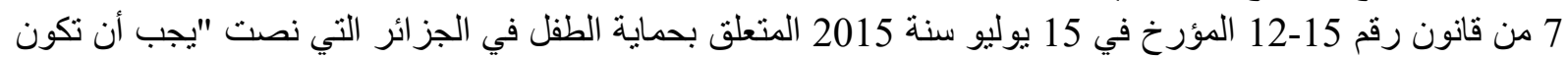

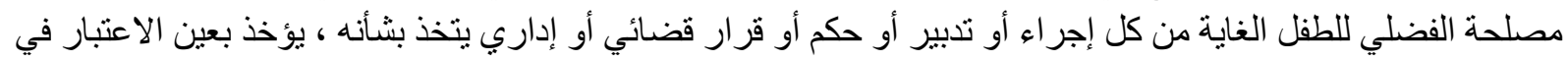

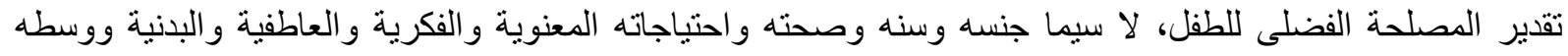

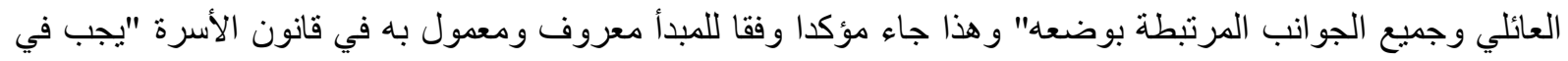

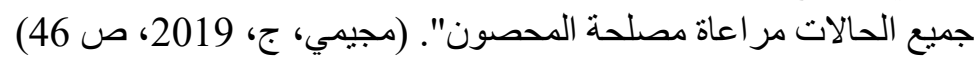

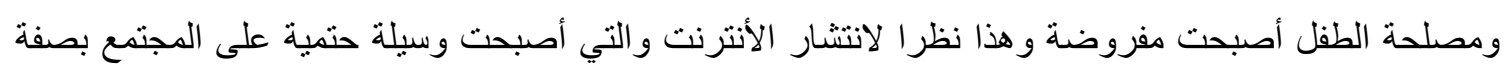

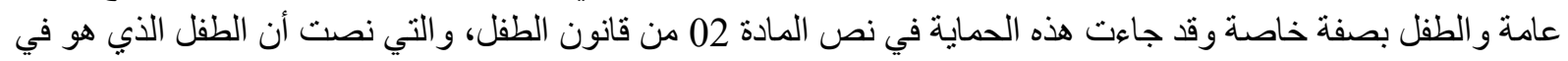

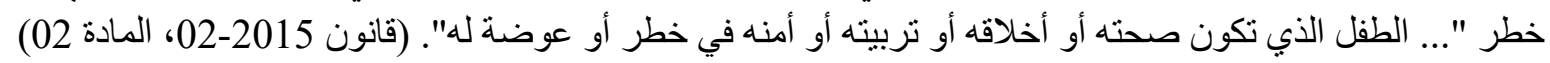
سوف نتناول بعض العقوبات المقررة للاستغلال الأطفال غبر الأنترنت. أولا- العقوبات المقررة على استغلال الاطفال عبر الانترنت: لم ينص المشرع الجزائري على عقوبات خاصة للاستغلال الطفل عبر الانترنت بل يمكن استخلاصها من القواعد المدات العامة المتمثلة :

\section{1 -جريمة تحريض طقل على العنف وفساد الأخلاق:}

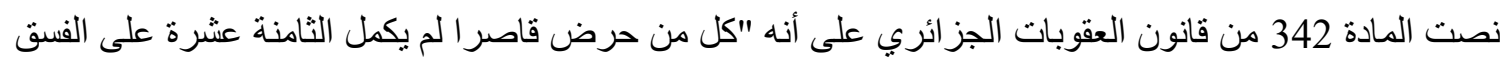

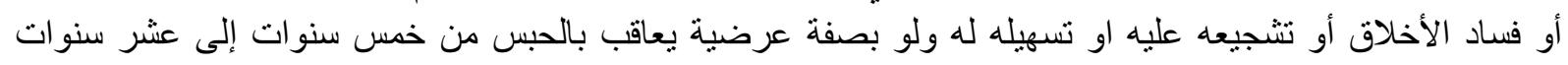

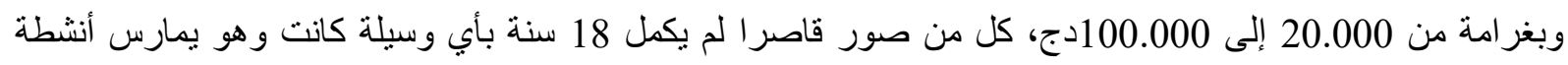

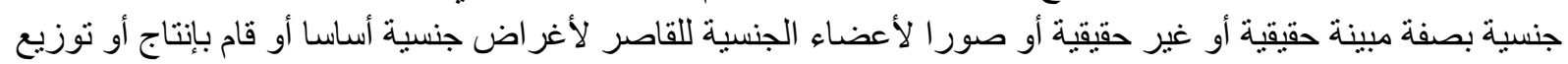

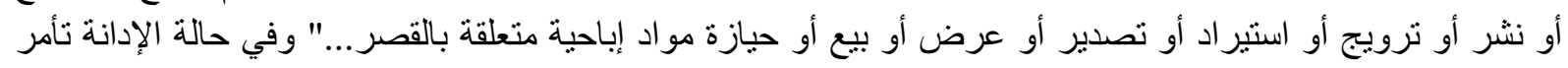

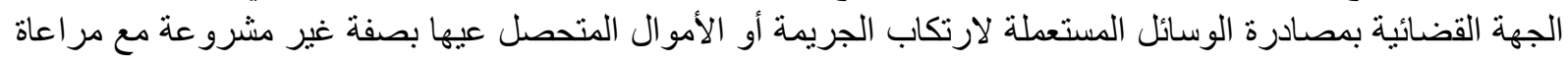

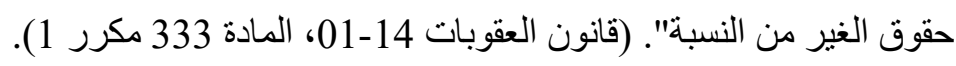

\section{2-عقوبة جرائم استغلال الأطفال على المخدرات :}

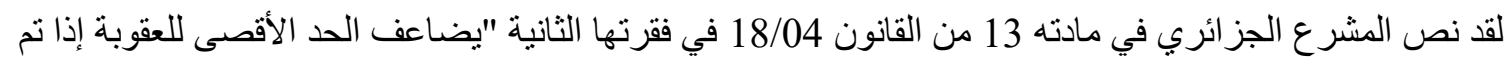

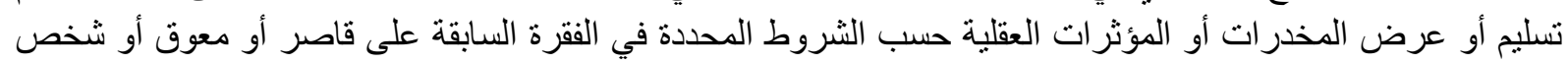

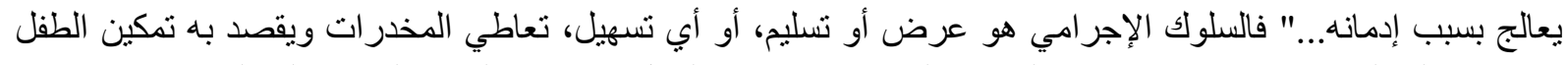

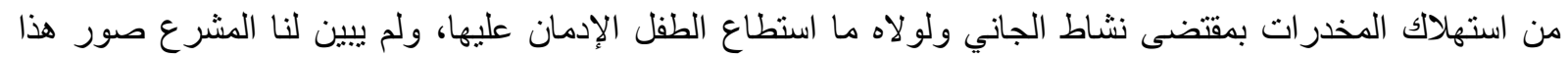

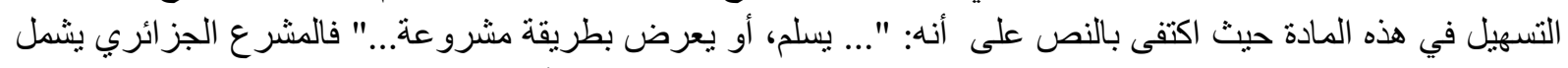

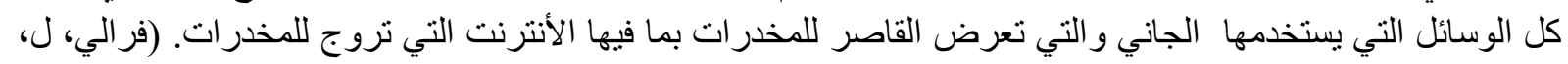

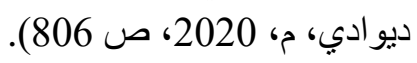
أولا- العقوبة الجزائية من التشهير عبر الانترنت :

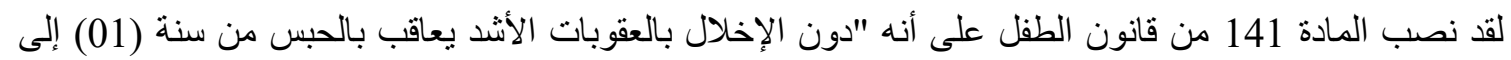

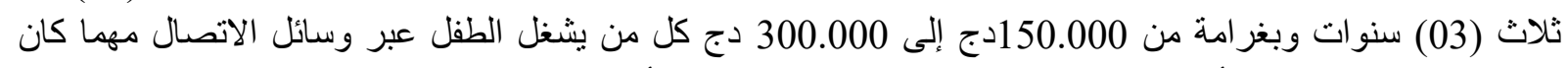

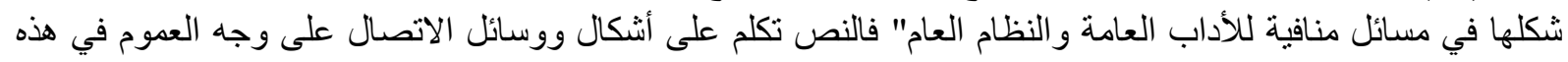

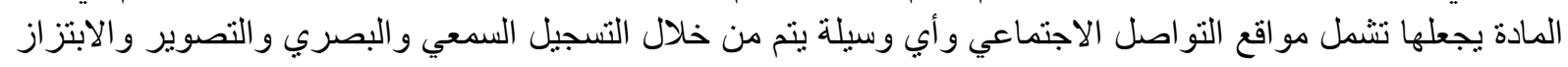

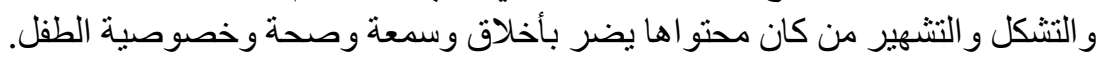

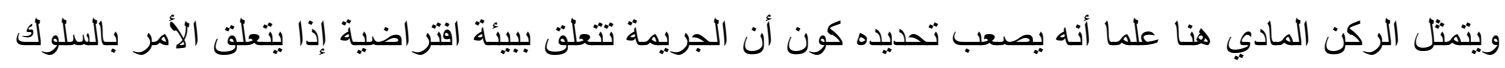

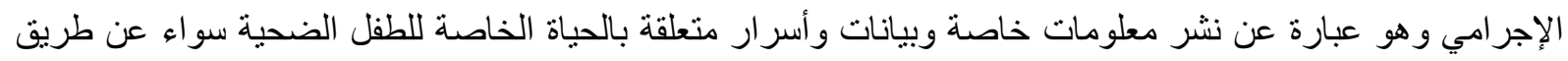

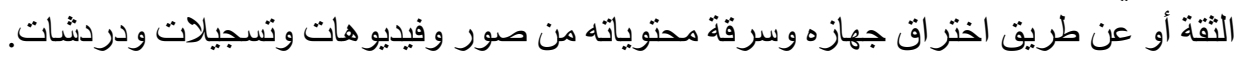


النتيجة الإجرامية: وتتم منى تم التشهير بالمعلومات عبر المو اقع التواصل الاجتماعي

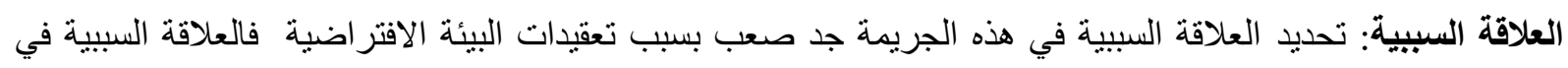
جريمة التشهير الرقمي تكون في تتفيذ الجانبي تهديده بالنشر و العلانية في موقع التو اصل العند الاجتماعي.

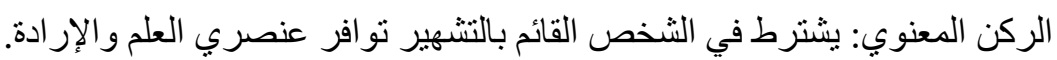

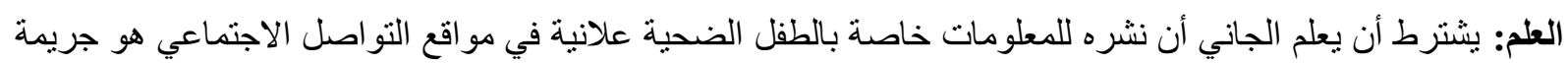

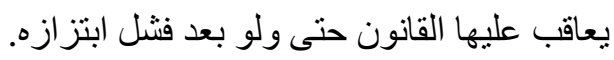

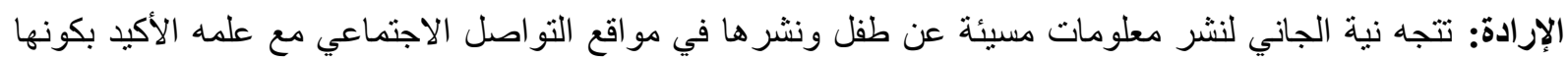

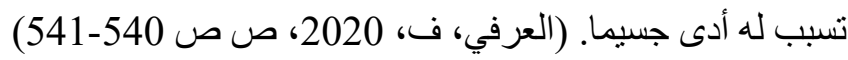
إن الحماية الردعية المفروطة لحماية الطفل لا تكفي لحماية الطفل من مضار الانترنت بل لا لادى من من تدخل المجتمع لزيادة

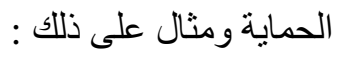
1 - 1 الوار الوالدين مع الطقل :

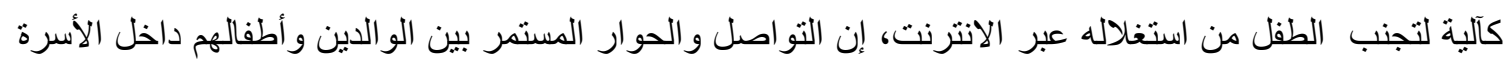

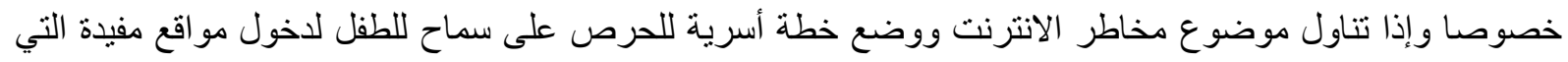

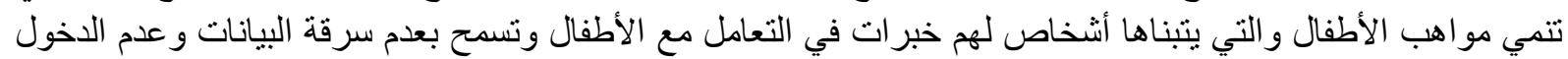

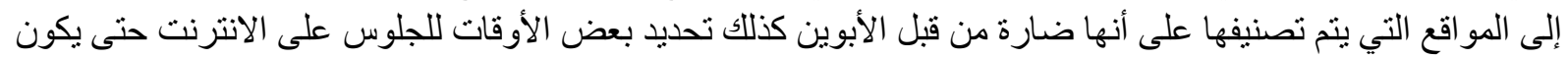

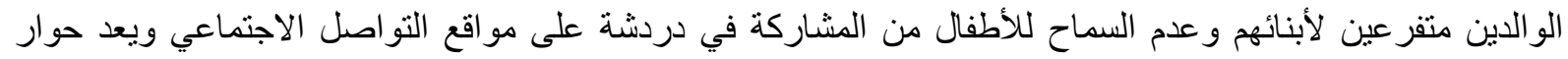

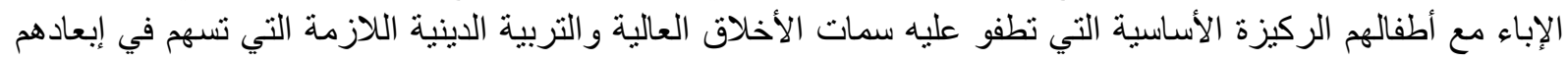
عن الرذيلة حتى يصبر الطفل رقيب على نفسيه وهو يتصفح الانترنت الأنس

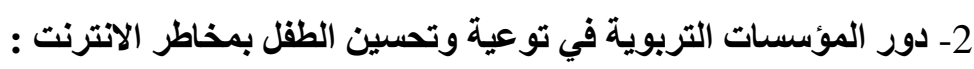

ويتجلى ذلك في توعية وتعليم الأطفال في تصفح الأنترنت و اضطلاعهم بمخاطر الانترنت في مناهج تعليمية

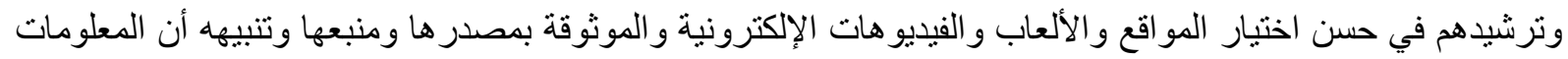

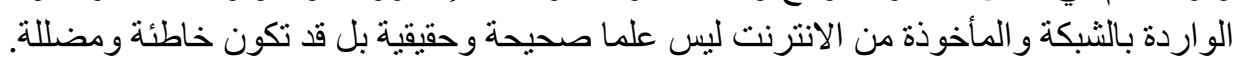

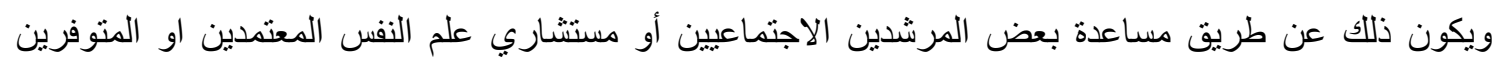

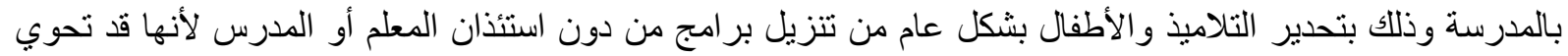

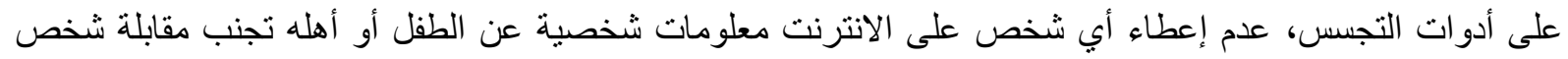

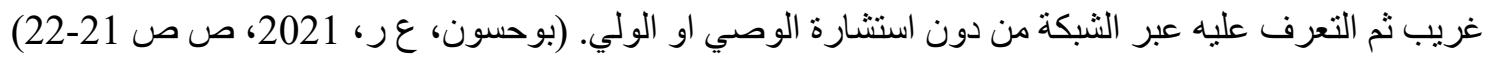

\section{ثانيا ـ الجهود الدولية لحماية الأطفال من الاستغلال عبر الانترنت :}

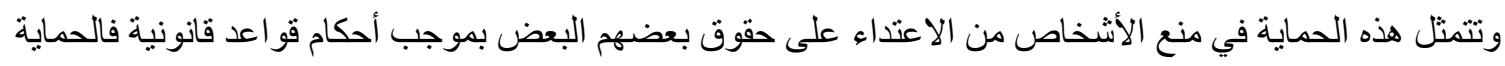

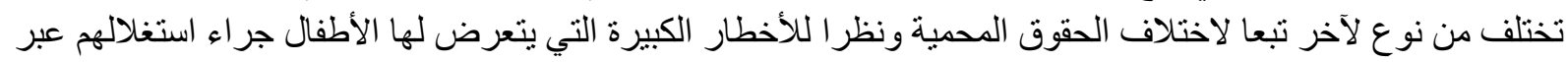

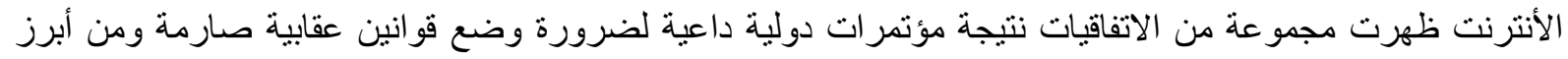

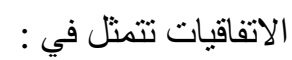

1-الاتفاقية الخاصة بحقوق الطفل (1989): تصدر الاتفاقيات العالمية لحقوق الطفل التي وفقت عليها الجئ الجز ائر إلى مثل هذه

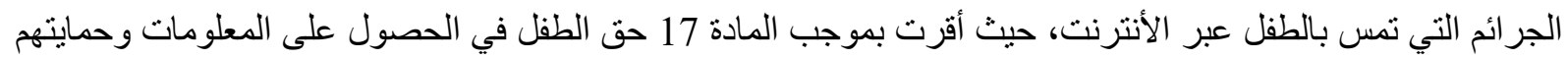

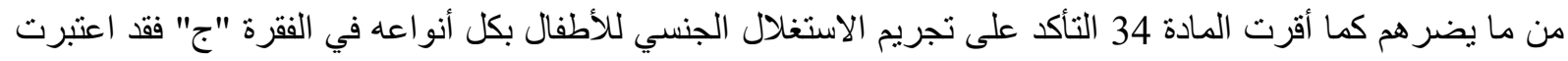

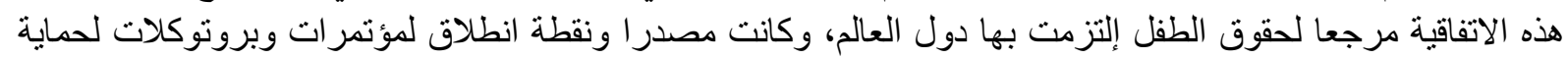
الطفل من كافة الاستغلال عبر مو اقع التو اصل الاجت التماعي. 2-الاتفاقيات الاقليمية المقررة لحماية الأطفال من مخاطر الانترنت: من مجمل الاتفاقيات :

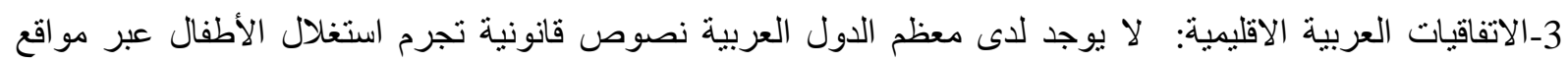

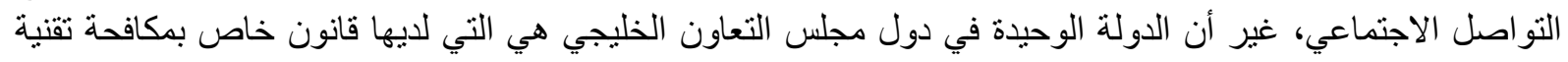




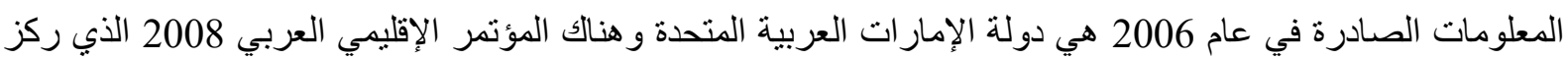

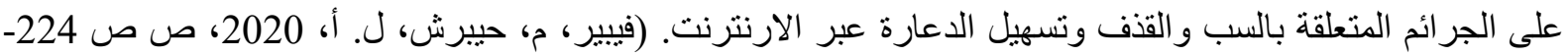

\section{ثالثا- جهود الهيئات الوطنية لحماية الأطفال من مخاطر الانترنت :}

تكاد تنعدم نشاطات المنظمات الوطنية المتخصصة في حماية الطفل من جرائم الأنترنت وهذا راجع إلى غياب

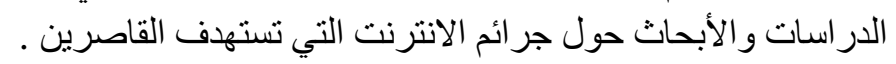

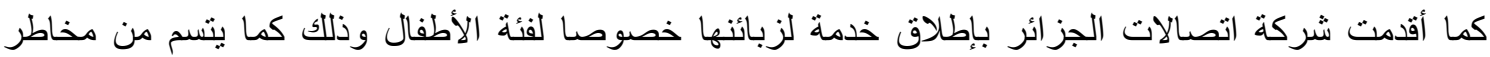

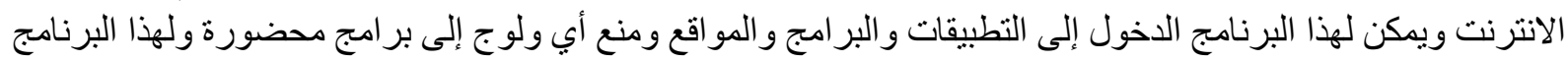

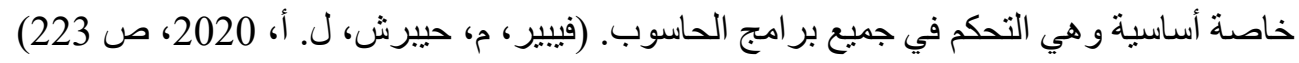

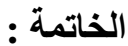

الجز ائر كغير ها من الدول تعمل على تطوير التكنولوجي الذي غزى العالم وهذا من أجل مكافحة الجر ائم المرتكبة ضد الأطفال عن طريق الأنترنت. إلا أن الدولة وحدها أصبحت غير كفيلة لمحاربة هذه الجر ائم بل ينبخي أن يلعب المجتمع و الأسرة و المدرسة دورا

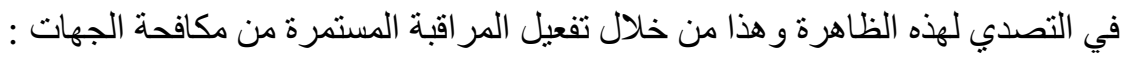

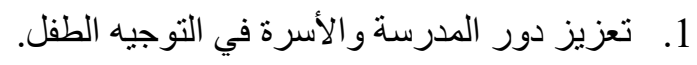
2. ضرورة سن خصوصي قانورنية جديدة تجرم ونعاقب صر الحة وبصورة مستقبلة استغلال الأطفال عبر مواقع التو اصل الاجتماعي. 3. وضع قو انين خاصة لحماية خصوصية وهويات الأطفال على الأنترنت. 
الأطفال يواجهون مستوى / البيانات UNICEF.org/ar اكبر من طر التعرض للأذى عبر الأنترنت في جائحة كوفيد

بن عبد الله زهراء، (2019)، الحماية الجزائة للطفل من جرائم الاستغلال الجنسي عبر شبكة الانترنت، مجلة الاجتهاد

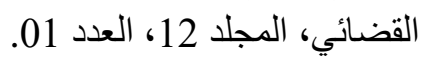

بوحسون عبد الرحمان، (2021)، أثر المعلمة الإكترونية على نمائي شخصية الطفل حاضرا ومستقبلا، مجلة العمارة

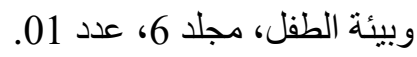

دحبران بن شاعة، أمليزي بعقوب، (2019)، الاطفال والأنترنت التأثثرات السلبية وطرق الحماية، مجلة التمكين الاجتماعي (جامعة الأغو اط)، المجلد الأول، العدد الثناني.

رصاع فتيحة، (2012-2013)، الحماية الجنائية للمعلومات على شبكة الانترنت، مذكرة لنيل شهادة الماجستير في العلوم القانونية، جامعة أبو بكر بلقايد، تلمسان، السنة الجامعية.

فاطمة العرفي، (2020)، الحماية القانونية للحق في الخصوصية للأطفال من جريمة التشهير عبر المواقع التواصل، التصل الاجتماعي في القانون الجزائري، مجلة الاجتهاد القضائي، المجلد 12، لإن، العدد

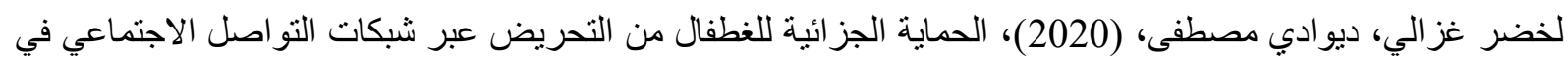

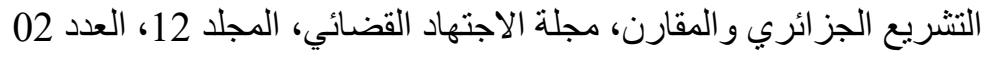

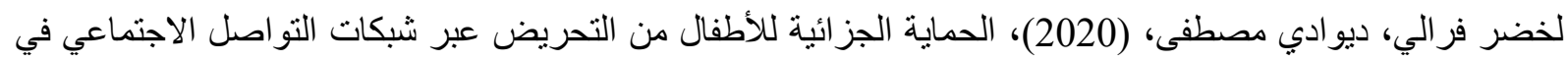

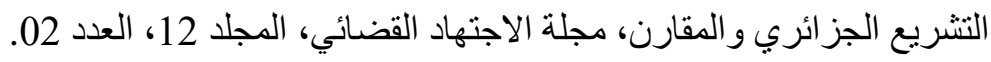

ليلة جيرجل، ماهو تعريف الأنترنت وفو ائده. mqaall.com/definition-internet-benefits المادة 02 من قانون رقم 2015-12 المؤرخ في 28 رمضان عام 1436 الموافق 15 يوليو سنة 2015، ويتعلق بحماية الطفل.

المادة 333 مكرر 1 من قانون العقوبات رقم 14-01 المعدل والمتمم للأمر رقم 156/66 و المتضمن قانون العقوبات،

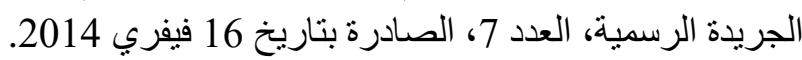

محمد الأزهر بلقاسمي، د. علي لفقير، (2018)، سوء معاملة الأطفال وإهمالهم، الآثار الناجمة عنها وكيفية الوقاية منها، مجلة الإبر اهيمي للعلوم الاجتماعية و الإنسانية، العدد 02.

مراد فريبير، لعزيز أحمد حيبرش، (2020)، الجهود الوطنية والدولية لحماية الطفل من مخاطر الأنترنت، مجلة التراث،

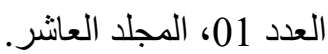

نجيمي جمال، (2019)، قانون حماية الطفل في الجزائر تحليل وتأصيل مادة بمادة القانون رقم 15-12 المؤرخ في 15 فئرة

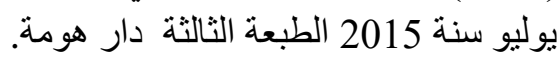

نقيب نور الإسلام، (2014-2015)، الآليات القانونية لحماية الطفل في الجزائر، مذكرة نيل شهادة الماجستير، كلية الحقوق، بن يوسف بن خدة. 